\title{
Sustainable Development Goals and the Study of Economic Inequality
}

\author{
Ravi Kanbur ${ }^{1}$ \\ Published online: 8 July 2020 \\ (C) Springer Science+Business Media, LLC, part of Springer Nature 2020
}

\begin{abstract}
This paper is an introduction to a special issue of the Journal of Economic Inequality which contains a selection of articles published in the Journal which bring economic perspectives and methods to bear on dimensions of inequality highlighted in the Sustainable Development Goals. The papers show that the study of economic inequality has much to contribute to the global policy discourse which is underpinned by the SDGs.
\end{abstract}

Keywords Inequality · Income distribution · Sustainable development goals · Gender inequality · Education and health inequalities · Inequality of opportunity

JEL Codes D31 $\cdot \mathrm{D} 63 \cdot \mathrm{I} 32 \cdot \mathrm{J} 71 \cdot \mathrm{O} 1 \cdot \mathrm{Q} 01$

\section{Introduction}

The Sustainable Development Goals (SDGs) are now part of the fabric of global policy discourse. They were adopted by United Nations Member States in 2015, as an anchor of the 2030 Agenda for Sustainable Development. The SDGs developed from the Millennium Development Goals (MDGs) of 2000-2015. The evolution was towards a broader and deeper agenda. There are $17 \mathrm{SDGs}$ compared to $8 \mathrm{MDGs}$. And certain issues which were not prominent in the MDGs are now center stage in the SDGs. One such issue is that of inequality. SDG-10 is specifically about inequality. It is entitled "Reduced Inequalities". But many others of the SDGs are also closely entwined with inequality.

Inequality is multidimensional in its outcomes and causes, encompassing the economic, the social and the political. Economic forces are not of course the only ones playing on inequality, but they are important by themselves and in conjunction with others. The study of the economic dimension of inequality has a long and distinguished history. This year is the

Ravi Kanbur

sk145@cornell.edu

1 Department of Applied Economics and Management and Department of Economics, Cornell University, Ithaca, NY, USA 
100th anniversary of a classic paper by Hugh Dalton (1920), which introduced explicit normative considerations into the measurement of inequality. Since that time economists have contributed to a wide ranging exploration of inequality. There has indeed been an expansion and flowering of this research over the last 20 years. In 2003 the Journal of Economic Inequality (JOEI) was founded as a vehicle for this research, and in 2005 the Society for the Study of Economic Inequality was founded to bring together economists working in this area.

Thus the prominence of inequality in the global policy discourse and the acceleration of research into economic inequality over the last two decades have been in step with each other. This special issue of JOEI marks this co-evolution by bringing together 6 papers previously published in the journal which speak to the inequality concerns of the SDGs. This leads to the question of how the research can better orient itself to the policy concerns, and in turn whether research highlights elements that are underemphasized or missing in the policy discourse. The plan of this overview and introduction is as follows. Section 2 gives an account of the extent and nature of the inequality orientation of the SDGs. Section 3 turns to research on economic inequality, and gives a brief account of the evolution of this research over the long haul and in the near past. Section 4 introduces the 6 papers from JOEI which form this special issue. Section 5 concludes.

\section{A Century of Research on Economic Inequality}

Questions of inequality and its assessment go back to antiquity. Book 5 of Aristotle's Nicomachean Ethics treats of distributive justice. Aristotle's contemporary, the great Indian writer on state craft Kautilya, also addresses distributional questions when setting out the responsibilities of the ruler:

"He shall maintain, at state expense, children, the old, the destitute, those suffering from adversity, childless women and the children of destitute women." (Rangarajan 1992, p. 182).

The question of inequality and the poor has been ever present in history, right up to the nineteen century writings of John Stuart Mill, Henry George and Alfred Marshall.

But inequality analysis in its modern form goes back a century, perhaps a "long century". The period begins with the contributions of Pareto (1898) and Gini (1912), and includes the equally classic empirical study of poverty in the English city of York by Rowntree (1901). Exactly 100 years ago, Hugh Dalton published his classic paper in the Economic Journal (Dalton 1920) which formalized axioms of income inequality measurement to address the disparate measures used by the growing number of empirical studies on income inequality. The dynamics of inequality was also under study in the interwar period, with Gibrat's (1931) volume Les Inégalités économiques, and Champernowne's celebrated work at this time on his fellowship thesis, which was not published till after the war (Champernowne 1953).

Interest in the analysis of inequality continued after the war, for example in the seminal work of Kuznets (1955), who not only put forward the much contested "Kuznets hypothesis" on an inverse- $U$ relationship between income inequality and per capita income as a country develops, but also set out the requirements for income distribution data:

First, the units for which incomes are recorded and grouped should be familyexpenditure units, properly adjusted for the number of persons in each..... Second, the distribution should be complete, i.e., should cover all units in a country rather than a segment either at the upper or lower tail. Third, if possible we should segregate the units 
whose main income earners are either still in the earning or already in the retired stages of their life cycle..... Fourth, income should be defined as it is now for national income in this country, i.e., received by individuals, including income in kind, before and after direct taxes, excluding capital gains. Fifth, the units should be grouped by secular levels of income, free of cyclical and other transient disturbances....Furthermore, if one may add a final touch to what is beginning to look like a statistical economist's pipe dream, we should be able to trace secular income levels not only through a single generation but at least through two-connecting the incomes of a given generation with those of its immediate descendants. (pp. 1-2)

Despite the interest of Kuznets and other scholars in the 1950s, it was the 1960s and 1970s that brought a flowering of the literature on inequality and poverty, and income distribution broadly defined. The early work of Tony Atkinson, in his classic 1970 article, followed on the tradition of Hugh Dalton in laying the normative foundations of inequality measurement (Atkinson, 1970). Amartya Sen (1973) also led the way in inequality measurement, further adding to the literature on poverty measurement (1976). Indeed the question of poverty and inequality have always been entwined in economics, in positive as much as in normative analysis. The Indian Third Five year Plan (1961-1966) incorporated distributional and especially poverty concerns. In the West, the civil rights movement in the US ignited distributional concerns seen through the lens of race. And assessment of policy interventions also picked up steam, as in Atkinson's (1969) volume, Poverty in Britain and the Reform of Social Security.

However, after this burst of interest in distributional matters in the 1960s and 1970s, the 1980s and the 1990s saw a decline in interest. These were the "Reagan-Thatcher-Kohl" years of reaction against state intervention. The late 1980s and the early 1990s saw the birth and spread of the Washington Consensus, and Fukuyama promulgated his thesis of the "end of history" signaling with the fall of the Berlin Wall a total victory of liberal politics and market economics (Fukuyama 1992). But, as noted in Kanbur (2001), 'The end of history lasted for such a short time." Not only were the excesses of the free market doctrine questioned as the result of disastrous outcomes in many places, the rising inequality which accompanied it was also brought center stage in empirical work, heralding a new era of focus on inequality and inequality research from the late 1990s onwards.

Thus the justly celebrated paper by Piketty and Saez (2003) set out the sharply rising trend of inequality in the US from the mid-1980s onwards. A decade later, Piketty (2014) took the world by storm making a rock star out of an inequality economist. The popular success of the book, despite being filled with charts and graphs, captured the zeitgeist of the period. In the last years of the decade, the launch of the World Inequality Report (Facundo et al. 2018) crystallized the rising interest in academic and in policy circles on questions of inequality. Most recently, Deaton and Case's (2020) work on "Deaths of Despair" has highlighted the connections between economic and health inequalities. Gender and race dimensions of inequality have resurfaced, in particular in the work on inequality of opportunity (Roemer 1998). The second Handbook of Income Distribution (Atkinson and Bourguignon 2015) was published, heralding further professional recognition of this area of research.

In keeping with this turn towards inequality analysis and research, the Journal of Economic Inequality was launched in 2003. In his Foreword to the very first issue, Amartya Sen captured the spirt of the times:

The subject of economic inequality is not only extraordinarily important on its own, it also links closely with many other topics in the social sciences....[T]he field of 
inequality studies is also extremely rich, with continuing contributions on conceptual and theoretical issues, on one side, and far-reaching investigations of empirical problems, on the other.... When we add to this the rich possibility of positively influencing related areas of economic and social studies, for which an understanding of inequality is important, it is easy to see why this journal can make a major difference to the social sciences. (Sen 2003, p. 1)

Sen's foreword highlights another key aspect of research into the economics of inequality-it goes beyond pure measurement and evaluation to an investigation of the causes of inequality and poverty. Furthermore, it connects deeply to the policy domain. As policy makers became more interested in distributional questions they, and their advisors, have turned to the academic and analytical literature for insights on measurement and on causality, most specifically on the consequences of different policy instruments. This is seen in many different ways within countries, but at the global level there can be no clearer indication of the importance of the issue than the extent to which it has been adopted in the discourse on the Sustainable Development Goals, to which we now turn.

\section{Inequality and the SDGs}

The evolution of the global policy discourse from the MDGs in 2000 to the SDGs in 2015 has been discussed extensively in the literature. Kanbur et al. (2018, pp. 34-35) give the following summary account:

The push to take a broad perspective on well-being, and especially in the measurement of development progress, goes back at least as far as the basic needs indicators and physical quality of life indexes in the 1970s....Agencies like the World Bank still gave primacy to national income per capita as a measure of development, but this began to change during the $1980 \mathrm{~s} \ldots$. The move towards multi-dimensional evaluation....culminated in the Millennium Development Goals...in September $2000 \ldots . .$. T] he scope of the goals....broadened when considering what to do after 2015, as interested parties brought to the fore key elements they considered were left out of the MDGs. In September, 2015, the United Nations General Assembly adopted Resolution 70/1, entitled "Transforming Our World: the 2030 Agenda for Sustainable Development".

The 17 SDGs which emerged out of this process now help to structure much of the policy discourse, and not only about the development process, since the ambition of the SDGs is to be truly global, encompassing both developing and developed countries. One of the key elements left out of the discussion around the MDGs was inequality, and this has taken center stage in the SDGs. As noted at the start, SDG-10 is in fact entitled "Reduce Inequalities." In keeping with the broad structure of the SDGs, a number of targets are specified under the broad goal of reducing inequalities. For SDG-10 these include, for example:

By 2030, progressively achieve and sustain income growth of the bottom 40 per cent of the population at a rate higher than the national average.

Ensure equal opportunity and reduce inequalities of outcome, including by eliminating discriminatory laws, policies and practices and promoting appropriate legislation, policies and action in this regard. 
Adopt policies, especially fiscal, wage and social protection policies, and progressively achieve greater equality.

While the above appear to pertain specifically to economic dimensions of interpersonal inequality, other targets under SDG-10 make clear that a broader perspective is intended, including non-economic dimensions and inequality between countries:

By 2030, empower and promote the social, economic and political inclusion of all, irrespective of age, sex, disability, race, ethnicity, origin, religion or economic or other status.

Implement the principle of special and differential treatment for developing countries, in particular least developed countries, in accordance with World Trade Organization agreements.

Encourage official development assistance and financial flows, including foreign direct investment, to States where the need is greatest...

SDG-10 is the clearest statement of the global objective of reducing inequality economic inequality. But a number of other SDGs have inequality closely entwined with them. Box 1 gives a series of examples (the goal is followed by an illustrative target with implications for inequality).

The SDGs have increasingly become a touchstone not only in the development discourse but the discourse on human wellbeing more generally. They intersect with research and analysis across social science disciplines, and many research projects are motivated by and in some cases structured by the SDGs, individually or in categories. Thus, for example, the new journal Nature Sustainability published an editorial in 2018 entitled, "Tracking progress on the SDGs" (Editorial 2018). However, there are many areas of research, particularly in economics, which do not explicitly evoke the SDGs and yet are doing research which is relevant to the SDGs. This is to some extent the case in economic research on inequality. The topics covered overlap significantly with the SDGs, and the research sheds light on different aspects of the SDGs, and yet the link is not made. This is also the case with many publications in JOEI, as this special issue shows, and as this overview will now highlight.

\footnotetext{
SDG-1: "End poverty in all its forms everywhere"; "By 2030, eradicate extreme poverty for all people everywhere, currently measured as people living on less than $\$ 1.25$ a day."

SDG-2: "Zero hunger"; "By 2030, end hunger and ensure access by all people, in particular the poor and people in vulnerable situations, including infants, to safe, nutritious and sufficient food all year round."

SDG-3: "Ensure healthy lives and promote well-being for all at all ages"; "By 2030, reduce the global maternal mortality ratio to less than 70 per 100,000 live births."

SDG-4: "Quality education"; "By 2030, ensure that all girls and boys complete free, equitable and quality primary and secondary education leading to relevant and Goal-4 effective learning outcomes." SDG-5: "Achieve gender equality and empower all women and girls"; "Undertake reforms to give women equal rights to economic resources, as well as access to ownership and control over land and other forms of property, financial services, inheritance and natural resources, in accordance with national laws."

SDG-8: "Promote inclusive and sustainable economic growth, employment and decent work for all"; "By 2030, achieve full and productive employment and decent work for all women and men, including for young people and persons with disabilities, and equal pay for work of equal value."
}

Box 1 Selection of SDGs Related to Inequality 


\section{A Selection of Articles from JOEI}

JOEI started publishing in 2003 with three issues per year. The growing supply of peer reviewed articles on the broad theme of inequality and poverty led to an expansion to four issues a year from 2008 onwards. The 64 issues to date have published hundreds of high quality articles and it is a tall order to select a small number from them to illustrate the interplay between research on the economics of inequality and inequality concerns in the SDGs. Many other could have been chosen, but the 6 articles presented in this issue are hopefully representative of what economics can bring to the study of inequality.

Tony Atkinson has already been identified as a giant in the study of inequality. His 1970 paper brought theoretical formalisms to bear on the measurement of inequality in a tradition going back to Dalton (1920) 50 years earlier. Tony passed away in 2017, depriving us of his continued contributions to the conceptual, empirical and policy analysis of inequality and distribution widely construed. Tony was the first President of the Society for the Study of Economic Inequality, and JOEI has published three special issues in his honor, with articles on themes Tony brought to the fore in the academic and policy discourse. In 2011 the journal published two special issues to mark the fortieth anniversary of his classic 1970 paper. The very first paper in that special issue was by Tony himself, and it is fitting that this is the first paper in this special issue.

The paper, "On Lateral Thinking" (Atkinson 2011), is characteristically sharp in addressing conceptual issues in a method that has been used in the study of inequality going beyond income, to inequality in health, education and other dimensions stressed in the SDGs. This is to apply measures of income inequality, such as the Atkinson (1970) measure, to other domains simply by analogy. Atkinson (2011) argues that "lateral thinking" is potentially fruitful, indeed the Atkinson (1970) measure exploited parallels from the measurement of risk (as did the formulation of Kolm 1969). But, "[a]t the same time, there may be dangers. The parallel may be deceptive" (Atkinson 2011, p. 319). Among several issues raised in translation of inequality measures to health inequality, is "the proportional nature of the inequality measures typically applied in studying income distribution", since "It does not seem plausible to suppose that health inequality indicators should be invariant with respect to equal proportionate changes." (p. 322).

However, Atkinson (2011) also points out a parallel that may be useful in conceptualizing and quantifying the multidimensional nature of inequality, as emphasized in the SDG discourse. This is the construct of a copula, from statistics. The key conceptual point is that the interdependence between income and health (or education, or other non-economic outcomes) is itself a key element of inequality, separate from inequality of income by itself and health by itself. The copula function from statistics provides a quantitative handle on the basic conceptualization and Tony, with his eye for conceptual clarity and applicability, advocates its use in applied and policy work.

As already noted, the question of poverty is never very far from distributional discourse in the policy arena. Even with a simple accounting perspective, where with given mean of the distribution of income an increase in inequality will lead to an increase in poverty under certain conditions, and the widespread decomposition of poverty changes into a mean change component and an inequality change component, the two are seen to be analytically and empirically entwined. In addition, the very first target of the very first SDG is "By 2030, eradicate extreme poverty for all people everywhere, currently measured as people living on less than $\$ 1.25$ a day." But this centrality of poverty brings great interest in questions of 
poverty measurement, especially in a global context where cross-country comparisons need to be made.

These issues of poverty measurement are taken up by Martin Ravallion in the second paper in this special issue, "Toward better global poverty measures" (Ravallion 2016). In the spirit of Kuznets (1955), Ravallion (2016) highlights data and conceptual questions in quantifying and assessing evolution of income distribution, this time with a focus on the lower end of incomes, and a global perspective. He starts with a brief account of the World Bank's approach to deriving a global poverty line (the "\$1.25 a day" in SDG-1) and then takes up three issues that arise in the method: the use of PPP (purchasing power parity) exchange rates for comparability across countries, the difficulties of arriving at a global consumption floor as the poverty standard, and incorporating social effects and relative concerns in measuring poverty. Ravallion's proposals for addressing these issue are rigorous and novel and call for close further study.

SDG-5 is dedicated to gender inequality. Among the many aspects of this dimension of inequality, the SDG specifies "access to ownership and control over land and other forms of property." This is the issue taken up by Carmen Diana Deere, Abena D. Oduro, Hema Swaminathan and Cheryl Doss in the next paper in the special issue, "Property rights and the gender distribution of wealth in Ecuador, Ghana and India." Not only is wealth inequality important in its own right, but it can also influence bargaining power within the household and thus outcomes for women and children such as health and nutrition. Deere et al. (2013) identify marital and inheritance regimes as central to the ability of women to accumulate wealth. Based on detailed surveys they identified wide variations in the share of a married couple's wealth owned by the woman across Ecuador (relatively high) on the one hand, and Ghana and the Indian state of Karnataka (relatively low) on the other. The explanation is located in the gender bias of different property and inheritance regimes. The authors conclude that "simply granting women basic property rights is not enough; rather, the specifics of marital and inheritance regimes matter greatly" (p. 262).

Gender is central to the patterns of inequality, but so are ethnic and racial factors. In the next article in the special issue Mariela Dal Borgo analyzes savings behavior, a key determinant of wealth accumulation, of Mexican Americans and African Americans at different points in the overall income distribution. The empirical finding is that the saving rates for these groups are lower than that of the reference group of White Americans, and that this gap widens as one goes up the income distribution. What explains the gap? In "Ethnic and racial disparities in saving behavior" Dal Borgo (2019) conducts an econometric analysis and finds that income, education and pension savings "account for the entire gaps at lower quantiles, but some unexplained racial gap remains at higher quantiles." Thus addressing inequalities in these characteristics would contribute to reducing inequality in savings rates and hence growing inequality in wealth and thus income in the future.

The attribution of gaps in key outcomes to a range of characteristics is the key methodological device in the literature on inequality of opportunity. The renaissance of the concept in economic research goes back to the contribution of Roemer (1998). The application to developing countries was given a boost by the World Bank's World Development Report 2006: Equity and Development, which was introduced to the readers of JOEI by Bourguignon, Ferreira and Walton (2007), the lead authors of the report. "Equal opportunity" is also a key component of SDG-10 on reducing Inequalities.

The next paper in the special issue, "Inequality of opportunity in adult health in Colombia", by Johanna Fajardo-Gonzalez (2016) combines investigation of inequality of opportunity with 
an investigation of the theme of SDG-3, "Ensure healthy lives." The paper also relates to Tony Atkinson's (2011) discussion, in the first paper in this special issue, of "lateral thinking" in using measures and methods developed for income inequality to health inequality. The paper uses a suite of measurement techniques from the inequality of opportunity literature, including stochastic dominance tests and decomposition of a dissimilarity index. In keeping with the terminology of the literature, the paper identifies "circumstances", in other word attributes over which an individual has no control, which determine health outcomes. These include, for example, parental education, region of birth and, particularly for urban areas, ethnicity.

The final paper of this special issue, "Public education provision, private schooling and income redistribution", by Andreoli et al. (2018), takes up the theme of SDG-4, "Quality Education". The goal intersects with an old debate in economics on the distributional consequences of public education provision. Using data from Italy, Andreoli et al. (2018) "test if universal availability of public education acts as a transfer in kind that redistributes income (i.e. is inequality-reducing) across households with school age children" (p. 554). One of the issues that arises is that if higher income households are more likely to take up educational services, especially at the upper-secondary level, then universal provision could have regressive consequences. Further complications arise when there is also private schooling. In this case, if wealthier parents opt into private schooling, the regressive redistributive effect of public provision needs to be recalibrated. The methodology the authors develop and deploy allows quantifications of the redistributive consequences of the relationship between educational achievement and income, returning once again to the Atkinsonian theme of "lateral thinking."

\section{Conclusion}

It should be clear that research on inequality from an economic perspective is well placed to speak to the concerns of the SDGs. Not only is SDG-10 specifically about inequality, but other SDGs also relate intimately to inequality in general and to income distribution in particular. Even when SDG concerns go beyond narrowly defined income inequality or income poverty, to health and education for example, or to inequalities across broad groups defined by gender, ethnicity or region of origin, there are vibrant components of the study of economic inequality which intersect with these concerns. The perspectives and methods of economic research, with emphasis on clear conceptual foundations and rigorous statistical methods, can help in the task of quantifying some of the targets in the SDGs, and in the task of identifying and assessing policy interventions to achieve these goals. However, the breadth and scope of the SDGs also challenge the economics of inequality on "lateral thinking"- to apply economic methods where appropriate, but to be careful on overreach, and to learn from the work of other disciplines on inequality. Tony Atkinson was right about this, as about so much else.

\section{References}

Andreoli, F., Casalone, G., Sonedda, D.: Public education provision, private schooling and income redistribution. J. Econ. Inequal. 16, 553-582 (2018)

Atkinson, A.B.: Poverty in Britain and the Reform of Social Security. Cambridge University Press, Cambridge (1969)

Atkinson, A., B.: On the measurement of inequality. J. Econ. Theory. 2, 244-263 (1970)

Atkinson, A., B.: On lateral thinking. J. Econ. Inequal. 9, 319-328 (2011) 
Atkinson, A.B., Bourguignon, F.: Handbook of Income distribution. Elsevier, Amsterdam (2015)

Case, A., Deaton, A.: Deaths of despair. Princeton University Press, Princeton (2020)

Champernowne, D.: A model of income distribution. Econ. J. 63(250), 318-351 (1953)

Dal Borgo, M.: Ethnic and racial disparities in saving behavior. J. Econ. Inequal. 17, 253-283 (2019)

Dalton, H.: The measurement of the inequality of incomes. Econ. J. 30(119), 348-361 (1920)

Deere, C.D., Oduro, A.D., Swaminathan, H., Doss, C.: J. Econ. Inequal. 11, 249-265 (2013)

Editorial: Tracking progress on the SDGs. Nat. Sustain. 1, 377 (2018)

Facundo, Alvaredo et al. World inequality report. (2018) https://wir2018.wid.world/files/download/wir2018-fullreport-english.pdf Accessed 31 May 2020

Fajardo-Gonzalez, J.: Inequality of opportunity in adult health in Colombia. J. Econ. Inequal. 14, 395-416 (2016)

Fukuyama, F.: The end of history and the last man. Free Press, New York (1992)

Gibrat, R.: Les Inégalités économiques. Recueil Sirey, Paris (1931)

Gini, C. Variabilità e mutabilità. Reprinted in Pizetti, E.; Salvemini, T., eds. (1955). Memorie di metodologica statistica. Libreria Eredi Virgilio Veschi, Rome (1912)

Kanbur, R.: Economic policy, distribution and poverty: the nature of disagreements. World Dev. 29(6), 10831094 (2001)

Kanbur, R., Patel, E., Stiglitz, J.E.: Sustainable development goals and the measurement of economic and social; Progress. In: Stiglitz, J.E., Fitoussi, J.-P., Durand, M. (eds.) For good measure: advancing research wellbeing metrics beyond GDP, pp. 33-48. OECD Publishing, Paris (2018). https://doi.org/10.1787 /9789264307278-en

Kolm, S.C.: The optimal production of social justice. In: Margolis, J., Guitton, H. (eds.) Public economics. Macmillan, London (1969)

Kuznets, S.: Economic growth and income inequality. Am. Econ. Rev. 45(1), 1-28 (1955)

Pareto, V.: Cours d'economie politique. J. Polit. Econ. 6, 549-552 (1898)

Piketty, T.: Capita in the twenty-first century. Harvard University Press, Cambridge (2014)

Piketty, T., Saez, E.: Income Inequality in the United States, 1913-1998. Q. J. Econ. CXVIII(1), 1-39 (2003)

Rangarajan, L.N.: Kautilya: the Arthashastra. Penguin, New Delhi (1992)

Ravallion, M.: Toward better global poverty measures. J. Econ. Inequal. 14, 227-248 (2016)

Roemer, J.: Equality of opportunity. Harvard University Press, Cambridge, MA (1998)

Rowntree, S.: Poverty a study of town life, Centennial Edition, (Reprinted Edition) edn. Policy Press, Bristol (1901) 2000

Sen, A.: On economic inequality. Oxford University Press, New York (1973)

Sen, A.: Poverty: an ordinal approach to measurement. Econometrica. 44(2), 219-223 (1976)

Sen, A.K.: Foreword. J. Econ. Inequal. 1(1), 1 (2003)

Publisher's Note Springer Nature remains neutral with regard to jurisdictional claims in published maps and institutional affiliations. 